\title{
Voluntary lung function screening to reveal new COPD cases in southern Italy
}

\author{
This article was published in the following Dove Press journal: \\ International Journal of COPD \\ II July 2017 \\ Number of times this article has been viewed
}

\section{Alberto Capozzolo \\ Giorgio Castellana \\ Silvano Dragonieri \\ Pierluigi Carratù \\ Vito Liotino \\ Maria Rosaria Vulpi \\ Lorenzo Marra \\ Emanuela Resta \\ Pierluigi Intiglietta \\ Onofrio Resta}

Department of Cardiac, Thoracic and Vascular Science, Institute of

Respiratory Disease, School of

Medicine, University of Bari, Bari, Italy
Background: Underdiagnosis of COPD is a relevant issue, and most frequently involves patients at early stages of the disease. Physicians do not routinely recommend smokers to undergo spirometry, unless they are symptomatic.

Aims: To investigate the effectiveness of voluntary lung function screening in bringing to light patients with previously unknown COPD and to evaluate the relationships among symptoms, smoking status, and airway obstruction.

Methods: A voluntary screening study for COPD was conducted during two editions of the annual Fiera del Levante (2014 and 2015), an international trade fair in Bari. Subjects were eligible for the study if they fulfilled the following inclusion criteria: age $\geq 35$ years, smoker/ ex-smoker $\geq 5$ pack-years (PYs), or at least one chronic respiratory symptom (cough, sputum production, shortness of breath, and wheezing). A free post- $\beta_{2}$-agonist spirometry test was performed by trained physicians for each participant using portable spirometers. Post- $\beta_{2}$-agonist forced expiratory volume in 1 second $\left(\mathrm{FEV}_{1}\right)$ :forced vital capacity ratio $<0.7$ was chosen to establish the diagnosis of COPD. Sensitivity, specificity, and negative and positive predictive values (NPVs and PPVs) of symptoms for the presence of obstruction were calculated.

Results: A total of 1,920 individuals were eligible for the study; 188 subjects (9.8\%) met COPD criteria. There was a $10.4 \%$ prevalence of COPD in subjects with one or more symptoms who had never smoked or smoked $\leq 5$ PYs. Among COPD patients, prevalence of symptoms increased in the presence of $\mathrm{FEV}_{1}<80 \%$. COPD smokers were more symptomatic than smokers without COPD. Sensitivity and specificity in all subjects with one or more symptoms were $87 \%$ and $32 \%$, respectively, whereas in smoker subgroups, sensitivity and specificity were $71 \%$ and $41 \%$ ( $\geq 5$ PYs) and $74 \%$ and $35 \%$ ( $\geq 10$ PYs), respectively. In all subjects, the presence of at least one symptom was associated with a low PPV for COPD of $11 \%$, but a very high NPV (96\%). These data did not change if the analysis was limited to smokers.

Conclusion: Voluntary public lung function screening programs in Italy are effective, and may detect a large number of undiagnosed subjects with COPD in early stages. In our population, COPD symptoms had low specificity and PPV, even considering smokers only.

Keywords: COPD underdiagnosis, COPD early stages, screening, spirometry

\section{Introduction}

COPD is characterized by airflow obstruction, and it is an important cause of mortality and disability worldwide. ${ }^{1}$ COPD should be suspected in subjects aged over 40 years with any of the following signs: 1) persistent and progressive dyspnea, typically worsened by physical exercise; 2) chronic cough, which may be intermittent and may be unproductive, recurrent wheeze; 3 ) chronic sputum production with any pattern; 4) recurrent lower respiratory tract infections; 5) a history of risk factors, such as host factors (eg, genetic factors, congenital/developmental abnormalities), tobacco smoke, 
smoke from home cooking and heating fuels, occupational dust, vapors, fumes, gases, and other chemicals; and 6) family history of COPD and/or childhood factors (ie, low birth weight, childhood respiratory infections). ${ }^{2}$

Cigarette smoking is one of the leading causes of respiratory diseases in Italy. In 2015, the Italian National Institute of Health found $25.1 \%$ smoking prevalence in Italian males and $16.9 \%$ in females, for a total of $20.8 \% .^{3}$ Tobacco smoke is the main risk factor for developing COPD, though some evidence suggests that other risk factors, such as indoor air pollution, occupational exposure, and passive smoking, are relevant, ${ }^{4-6}$ especially in developing countries. Therefore, an estimated $25 \%-45 \%$ of patients with COPD have never smoked. ${ }^{7}$ Nevertheless, that group, considered at low risk, is usually excluded from screening studies of COPD. The gold standard for COPD diagnosis is postbronchodilator (post-BD) spirometry performed in those patients suspected of having COPD, allowing the detection of early-stage lung disease. ${ }^{2,8}$ The ongoing strategy aims to identify undiagnosed COPD. ${ }^{2}$ Underdiagnosis most frequently involves patients at early stages of COPD. Interestingly, about $95 \%$ of those in stage 1 (mild airflow limitation) and $80 \%$ of those in stage 2 (moderate airflow limitation) remain undiagnosed..$^{9}$ The main reason is that physicians do not routinely recommend smokers to perform spirometry ${ }^{10,11}$ unless they are symptomatic, particularly with dyspnea. Moreover, mild and even moderate COPD can occur without complaints or symptoms, also hampering early diagnosis. ${ }^{12}$ The period of most rapid decline in lung function may occur much earlier than previously thought, and it is during this period that aggressive testing strategies, smoking-cessation efforts, and the initiation of treatments may be beneficial. ${ }^{13,14}$ One method for early detection is a voluntary public screening program. An example of voluntary screening is a respiratory therapist setting up a booth at a fair and offering spirometry to anyone who walks by and is interested. ${ }^{15,16}$ In Italy, few screening programs, usually based on regional cohorts, have been performed to assess the prevalence of COPD, ${ }^{17-19}$ and predictive models have been based on administrative databases. ${ }^{20}$ Currently, there is no consensus on how, when, and where public screening with spirometry should be implemented. Based on these factors, this study was performed with the primary aim of investigating the effectiveness of voluntary lung function screening in bringing to light patients with previously unknown COPD. Secondarily, we aimed to evaluate the relations among symptoms, smoking status, and airway obstruction.

\section{Materials and methods}

A voluntary screening study for COPD was carried out during two editions (September 2014 and 2015) of the yearly Fiera del Levante, an international trade fair in Bari that gathers visitors from many regions of southern Italy (mainly Puglia, Basilicata, Campania, and Calabria) over 8 days. In 2015, Puglia had a resident population of 4 million, Basilicata 575,000, Campania 5.9 million, and Calabria 2 million. The percentage of smokers in the south and islands is $26.2 \%$ for men and 17.2 for women. ${ }^{3}$ With regard to environmental pollution, Italy has the highest concentrations of pollutants in Europe, with registration of the highest levels in the northern regions. ${ }^{21}$

In order to offer lung function testing to a large number of visitors, a program entitled "Breath Days" was planned by the principal investigators. Permission was obtained to place a testing station in a central location of the fair, and the program was advertised in local newspapers. The study was approved by the institutional review board of Bari University General Hospital and by the board of directors of the fair (Fiera del Levante). All participants provided written informed consent.

Subjects were eligible for the study if they fulfilled the following inclusion criteria: age $\geq 35$ years, smoker/exsmoker $\geq 5$ pack-years (PYs), or at least one chronic respiratory symptom (cough, sputum production, shortness of breath, and wheezing). Noninclusion criteria were previous diagnosis of obstructive lung disease and/or treatment with long-acting BDs. Individuals unable to perform spirometry were excluded. Complete demographic data were collected for each subject included. Initially, all subjects underwent a brief health survey consisting of questions about previous diagnoses of chronic respiratory disease Afterward, Charlson Comorbidity Index score was calculated according to the specifications described by Charlson et al, ${ }^{22}$ and subsequently a questionnaire on four respiratory symptoms items (yes/no) - presence of cough, sputum production, shortness of breath, and wheezing - was completed. Data on past and present smoking habits were also collected. Participants were classified as current/ex-smokers if they had a smoking history of at least 5 PYs. Smokers without symptoms were classified as "healthy smokers". Never-smokers or those with $<5$ PYs were considered nonsmokers. Ex-smokers were former smokers who had not smoked for at least 6 months. ${ }^{23}$ To calculate PYs, the average number of cigarettes smoked per day was divided by 20 to obtain the number of packs per day and multiplied by the total number of years of smoking.

A free post-BD (0.4 mg inhaled salbutamol) spirometric test was performed by trained physicians for each participant 
using two portable spirometers (Spirolab II; Medical International Research, Waukesha, WI, USA). This device has been approved by the US Food and Drug Administration, ${ }^{24}$ meets 2005 America Thoracic Society/European Thoracic Society performance standards, and allows direct visualization of the flow-volume curve and expiration time..$^{25}$ The spirometers were regularly calibrated at the beginning of each workday, cleaned, and maintained according to the manufacturer's instructions. Participants underwent a minimum of three acceptable forced vital capacity (FVC) maneuvers. Efforts that were incomplete or in which the patient coughed were excluded, and at the end the largest FVC and the largest forced expiratory volume in one second $\left(\mathrm{FEV}_{1}\right)$ were retained. ${ }^{26}$ Reference spirometry values established by the European Coal and Steel Community were chosen.$^{27}$ The The Global Obstructive Lung Disease (GOLD) criterion of $\mathrm{FEV}_{1}$ :FVC ratio $<0.7$ after inhaled $\mathrm{BD}$ was chosen for COPD diagnosis. ${ }^{2}$ Finally, all subjects were divided in two groups: COPD and not COPD. COPD airflow-obstruction severity was based on GOLD staging criteria: $1, \mathrm{FEV}_{1} \geq 80 \%$ (mild); $2, \mathrm{FEV}_{1} \leq 50 \%-<80 \%$ (moderate) $3, \mathrm{FEV}_{1} \leq 30 \%-<50 \%$ (severe); and $4, \mathrm{FEV}_{1}<30 \%$ (very severe). ${ }^{2}$

\section{Statistical analysis}

Analyses were performed using SPSS 20 (IBM, Armonk, NY, US). A $P$-value $<0.05$ was considered significant. Univariate comparisons between COPD and not-COPD groups were performed by Student's $t$-test for independent samples and Mann-Whitney $U$-test for normally and abnormally distributed variables, respectively. Fisher's exact test was used for the analysis of categorical variables between two groups. Sensitivity, specificity, negative predictive values (NPVs), and positive PVs (PPVs) of symptoms for the presence of obstruction were calculated. Logistic regression was used to estimate the odds ratio for each symptom and smoking history of $\geq 5$ and $\geq 10$ PYs. The Cronbach $\alpha$-value used to assess the generalizability of the four considered symptoms items was $0.74 .^{28}$

\section{Results}

A total of 2,587 volunteers participated in this study (Figure 1); 572 subjects were excluded because they did not meet the inclusion criteria, 81 were unable to perform spirometry, and 14 did not sign informed consent. Among all subjects found eligible for the study, 188 (9.8\%) met COPD criteria after post-BD spirometry.

The characteristics of the study population are summarized in Table 1. The COPD group had more men and were

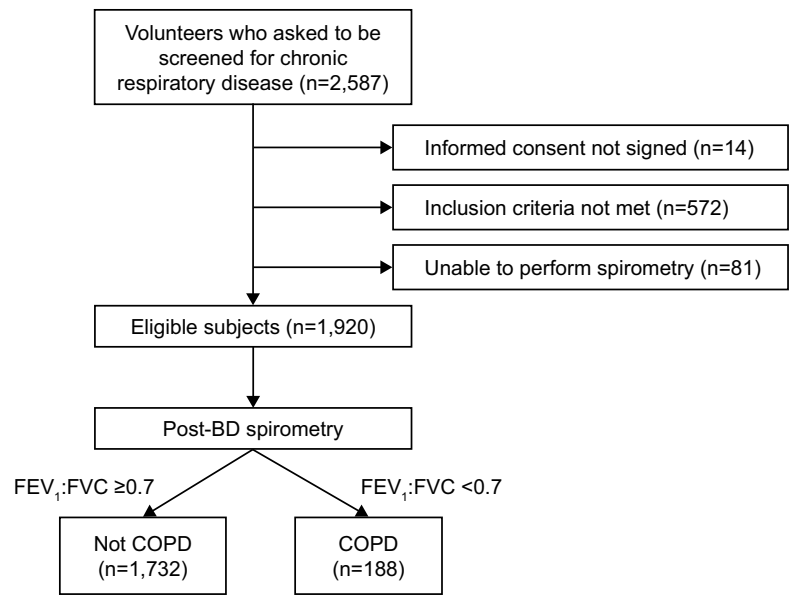

Figure I Design of the study.

Abbreviations: BD, bronchodilator ( $400 \mu \mathrm{g}$ salbutamol); $\mathrm{FEV}_{1}$, forced expiratory volume in I second; FVC, forced vital capacity.

Table I Characteristics of the study population

\begin{tabular}{|c|c|c|c|}
\hline Variables & $\begin{array}{l}\text { Not COPD } \\
(n=1,732)\end{array}$ & $\begin{array}{l}\text { COPD } \\
(n=188)\end{array}$ & $P$-value \\
\hline \multicolumn{4}{|l|}{ Demographic data } \\
\hline Mean age, years & $51.7 \pm 14.5$ & $61 \pm 10$ & 0.005 \\
\hline \multicolumn{4}{|l|}{ Age range, years } \\
\hline $35-39$ & $8.6(149)$ & $2.7(5)$ & 0.002 \\
\hline $40-49$ & $9.9(172)$ & $9.5(18)$ & NS \\
\hline $50-59$ & $24.5(423)$ & $26.6(50)$ & NS \\
\hline $60-69$ & $38(659)$ & $39.9(75)$ & NS \\
\hline$\geq 70$ & 19 (329) & $21.3(40)$ & NS \\
\hline Male & $56.4(976)$ & $72.3(136)$ & $<0.001$ \\
\hline BMI & $26.5 \pm 5.1$ & $26.8 \pm 5.4$ & NS \\
\hline \multicolumn{4}{|l|}{ Spirometric data } \\
\hline Post-BD FEV \% predicted & $100.6 \pm 16.5$ & $82.1 \pm 17.3$ & $<0.001$ \\
\hline Post-BD FVC\% predicted & $102.7 \pm 17$ & $103.1 \pm 14.9$ & NS \\
\hline Post-BD FEV & $80.7 \pm 5.9$ & $62.7 \pm 8.1$ & $<0.001$ \\
\hline \multicolumn{4}{|l|}{ History of smoking } \\
\hline Current smokers & $38.5(666)$ & $44.7(84)$ & NS \\
\hline Ex-smokers & $39.5(685)$ & $31.9(60)$ & 0.048 \\
\hline Nonsmokers & $22.0(38 I)$ & $23.4(44)$ & NS \\
\hline \multicolumn{4}{|l|}{ Smoking exposure } \\
\hline Pack-years & $14.3 \pm 13.9$ & $22.4 \pm 12.6$ & $<0.001$ \\
\hline \multicolumn{4}{|l|}{ Symptoms } \\
\hline Cough & $24.3(42 I)$ & $36.8(69)$ & $<0.001$ \\
\hline Sputum production & I5.3 (265) & $21.9(4 I)$ & 0.027 \\
\hline Shortness of breath & $37.1(643)$ & $52.7(99)$ & $<0.001$ \\
\hline Wheezing & $12 . \mid(2 \mid 0)$ & $18.6(35)$ & 0.015 \\
\hline Symptoms $\geq 1$ & $68.2(1,182)$ & $77.7(146)$ & 0.007 \\
\hline \multicolumn{4}{|l|}{ GOLD stage } \\
\hline 1 & - & $63.8(120)$ & - \\
\hline 2 & - & $36.2(68)$ & - \\
\hline \multicolumn{4}{|l|}{ Comorbidities } \\
\hline Charlson Comorbidity Index & $0.4 I \pm 0.72$ & $1.66 \pm 1.1$ & $<0.001$ \\
\hline
\end{tabular}

Note: Data presented as percentage (n) or mean (SD).

Abbreviations: NS, not significant; BMI, body-mass index; BD, bronchodilator; $\mathrm{FEV}_{\text {, }}$, forced expiratory volume in I second; FVC, forced vital capacity; GOLD, Global Obstructive Lung Disease. 
Table 2 Frequency of symptoms in smokers and nonsmokers

\begin{tabular}{|c|c|c|c|c|c|c|c|c|c|}
\hline \multirow[t]{2}{*}{ Variables } & \multicolumn{3}{|c|}{ Nonsmokers } & \multicolumn{3}{|c|}{ Smokers $\geq 5$ PYs* } & \multicolumn{3}{|c|}{ Smokers $\geq 10$ PYs* } \\
\hline & COPD & Not COPD & $P$-value & COPD & Not COPD & $P$-value ${ }^{\#}$ & COPD & Not COPD & $P$-value \\
\hline Subjects, n (\%) & $44(23.4)$ & $38 I(22)$ & & $144(76.6)$ & $\mathrm{I}, 35 \mathrm{I}(78.0)$ & & $128(68.1)$ & $957(55.3)$ & \\
\hline Mean age, years & $59.4 \pm 11.3$ & $48.3 \pm 13.5$ & $<0.001$ & $60.6 \pm 11.8$ & $52.4 \pm 14.9$ & $<0.001$ & $62.6 \pm 10.6$ & $53.8 \pm 12.7$ & $<0.001$ \\
\hline $\mathrm{FEV}, \%$ predicted & $85.2 \pm 14$ & $103.4 \pm 15.3$ & $<0.001$ & $79.1 \pm 16.4$ & $99.4 \pm 15.8$ & $<0.001$ & $76.1 \pm 15.2$ & $96.4 \pm 14.3$ & $<0.001$ \\
\hline BMI & $27.2 \pm 6.0$ & $25.4 \pm 5.3$ & NS & $26.6 \pm 5.7$ & $27.1 \pm 5.6$ & NS & $26.4 \pm 5.3$ & $27.5 \pm 5.8$ & NS \\
\hline \multicolumn{10}{|l|}{ Symptoms, \% (n) } \\
\hline Cough & I8.2 (8) & $26.8(102)$ & $\mathrm{NS}^{\#}$ & $42.4(61)$ & $23.6(319)$ & $<0.001$ & $44.5(57)$ & $27.6(264)$ & $<0.001$ \\
\hline Sputum production & $18.2(8)$ & $16(6 I)$ & NS" & $22.9(33)$ & I5.I (204) & NS & $23.4(30)$ & $20(191)$ & NS \\
\hline Shortness of breath & $75(33)$ & $55.4(211)$ & $0.015^{\#}$ & $45.8(66)$ & $32(432)$ & 0.001 & $47.7(6 I)$ & $34.2(327)$ & 0.003 \\
\hline Wheezing & $36.4(16)$ & $21(80)$ & $0.034^{\#}$ & $13.2(19)$ & $9.6(130)$ & NS & $7(9)$ & $10.1(97)$ & NS \\
\hline One or more symptoms & $100(44)$ & $100(381)$ & - & $70.8(102)$ & $59.3(801)$ & 0.007 & $74.2(95)$ & $65.1(623)$ & 0.046 \\
\hline
\end{tabular}

Notes: *Includes current/ex-smokers; "Fisher's exact test. If not specified, data presented as mean \pm SD.

Abbreviations: BMI, body-mass index; FEV , forced expiratory volume in I second; NS, not significant; PYs, pack-years.

on average 10 years older than the not-COPD group. FVC\% was similar between the COPD and not-COPD groups. All symptoms considered were more frequent in the COPD group. All subjects with COPD belonged to GOLD 1 (63.8\%) and $2(36.2 \%)$. Symptomatic COPD subjects were $77.7 \%$. Current cigarette smoking was similar between COPD and not-COPD subjects. However, if measured by PYs, cigarette smoking was higher in the COPD population.

Among never-smoker COPD subjects, higher average age and more frequent shortness of breath and wheezing were found. Conversely, COPD subjects in smoker subgroups had more frequent cough. Shortness of breath was always present in COPD subjects, including all subjects and subgroups. Wheezing was more present in COPD subjects in the nonsmoker group, showing no differences in all smokers comparing COPD with not-COPD subjects. COPD smokers were more symptomatic than not-COPD smokers (Table 2).

There was a $10.4 \%$ prevalence of COPD in subjects with at least one symptom, who had never smoked, or had smoked $\leq 5$ PYs. This percentage was similar when considering all subjects with at least one symptom (11\%) and smokers only (10.7\%) (Table 3). Healthy smokers had the lowest prevalence of COPD. Cough, sputum, shortness of breath, and wheezing were more frequent in moderate-COPD-stage cases compared to mild-stage cases (Table 4). Symptoms were also significantly associated with airway obstruction. Cough was the symptom that showed the greatest odds ratio [OR] for COPD in smoker subgroups (OR 2.38), whereas shortness of breath was highest when considering all subjects (OR 1.88). Moreover, smoking $\geq 10$ PYs showed an OR for association with COPD of 1.73 (95\% confidence interval [CI] 1.25-2.38) and was significantly greater than the OR for smokers $\geq 5$ PY (Table 5).

Table 6 shows the symptom sensitivity, specificity, and PVs for COPD in all subjects and in two subgroups of smokers ( $\geq 5$ and $\geq 10$ PYs). When all subjects were considered, the sensitivity and specificity of cough were $37 \%$ and $76 \%$, respectively. In the same group, a sensitivity of $53 \%$ was related to shortness of breath, with specificity of $63 \%$. Values of sensitivity and specificity for each symptom were similar in the two groups of smokers considered. For each symptom, even considering the presence of one or more symptoms, PPVs were low and NPVs high. Sensitivity and specificity in all subjects with one or more symptoms were $87 \%$ and $32 \%$ respectively, whereas in smoker subgroups, sensibility and specificity were $71 \%$ and $41 \%$ ( $\geq 5 \mathrm{PY}$ ), $74 \%$, and $35 \%$ ( $\geq 10 \mathrm{PY}$ ), respectively.

\section{Discussion}

To the best of our knowledge, this is the first broad COPD public screening of volunteers in Italy. Our study showed that $9.8 \%$ of adults who voluntarily participated in a public screening program had COPD and $77.7 \%$ had at least one symptom related to COPD. The south of Italy lacks population studies evidencing the prevalence of COPD. The regional health care information system database of Puglia

Table 3 Prevalence of COPD

\begin{tabular}{|c|c|c|c|}
\hline & $\mathbf{N}$ & $\begin{array}{l}\text { COPD } \\
\text { subjects (n) }\end{array}$ & $\begin{array}{l}\text { Prevalence } \\
\text { (\%) }\end{array}$ \\
\hline All subjects & 1,920 & 188 & 9.8 \\
\hline $\begin{array}{l}\text { Nonsmokers } \\
\text { (I or more symptoms)* }\end{array}$ & 425 & 44 & 10.4 \\
\hline $\begin{array}{l}\text { All subjects with } \\
\text { I or more symptoms }\end{array}$ & $\mathrm{I}, 328$ & 146 & II \\
\hline All smokers $\geq 5$ PYs & $\mathrm{I}, 35 \mathrm{I}$ & 144 & 10.7 \\
\hline Healthy smokers $\geq 5$ PYs & 592 & 42 & 7.1 \\
\hline All smokers $\geq 10 \mathrm{PYs}$ & $\mathrm{I}, 085$ & 128 & 11.8 \\
\hline Healthy smokers $\geq 10 \mathrm{PYs}$ & 367 & 33 & 9 \\
\hline
\end{tabular}

Note: *Nonsmokers without symptoms were not included in study population. Abbreviation: PYs, pack-years. 
Table 4 Percentage of symptoms in COPD cases by FEV,

\begin{tabular}{|c|c|c|c|}
\hline Symptom, \% (n) & $\begin{array}{l}\text { FEV }_{1} \geq \mathbf{8 0} \% \\
(n=\mid 20)\end{array}$ & $\begin{array}{l}\text { FEV }_{1}<80 \% \\
(n=68)\end{array}$ & $P$-value \\
\hline Cough & $30(36)$ & $48.5(33)$ & 0.012 \\
\hline Sputum production & $13.3(16)$ & $35.8(25)$ & $<0.001$ \\
\hline Exertional breathlessness & $4 I .7(50)$ & 72.I (49) & $<0.001$ \\
\hline Wheezing & $13.3(16)$ & 27.9 (19) & 0.019 \\
\hline
\end{tabular}

Abbreviation: $\mathrm{FEV}_{\mathrm{l}}$, forced expiratory volume in I second.

indicated a prevalence of $7 \%$ in the population aged over 40 years. ${ }^{29}$ The prevalence of COPD in people aged $\geq 45$ years in Puglia, according to data from the Quadro Project, was $3.1 \%{ }^{30}$ Considering this, our findings suggest that the organization of a voluntary public lung function screening program allowing participants to self-select for a "lung test" may be an effective approach to ensure high-yield detection of undiagnosed COPD.

In the current study, COPD nonsmoking subjects were $23.4 \%$ of all the COPD population. Although we know that, as indicated by McIvor and Tashkin, ${ }^{31}$ the presence of chronic respiratory symptoms in addition to the smoking habit is considered essential for many population-screening programs to identify patients at risk for COPD, ${ }^{32-35}$ our data, according to Ohar et al, ${ }^{36}$ suggest that we should have doubts toward this indication. Even the results of Bednarek et al indicated that limiting screening to smokers would have reduced the number of COPD diagnoses by $26 \%{ }^{37}$ Likewise, Whittemore et al reported that a quarter of COPD cases in the US occurred in never-smokers. ${ }^{38}$ Our data are also supported by two similar proportions of $22.9 \%$ and $23.4 \%$ in the UK and Spain, respectively. ${ }^{39,40}$

Foremost symptoms in our group of COPD nonsmokers were shortness of breath and wheezing and to a lesser extent cough and sputum. As known, COPD risk factors in nonsmokers may include genetic factors, outdoor air pollution (from traffic and other sources), environmental smoke exposure, biomass smoke, and occupational exposure. These factors probably played a crucial role in our nonsmokers.

Table 5 Odds ratios and $95 \% \mathrm{Cls}$ for having COPD

\begin{tabular}{llll}
\hline Symptom & $\begin{array}{l}\text { All subjects } \\
(\mathbf{n}=\mathbf{I}, \mathbf{9 2 0})\end{array}$ & $\begin{array}{l}\text { Smokers } \geq 5 \\
\text { PYs }(\mathbf{n}=\mathbf{I}, \mathbf{4 9 5})\end{array}$ & $\begin{array}{l}\text { Smokers } \geq \mathbf{I 0} \\
\text { PYs }(\mathbf{n}=\mathbf{I}, \mathbf{0 8 5})\end{array}$ \\
\hline Cough & $\mathrm{I} .8 \mathrm{I}(\mathrm{I} .32-2.48)$ & $2.38(\mathrm{I} .67-3.39)$ & $2 . \mathrm{I}(\mathrm{I} .45-3.07)$ \\
Sputum production & $\mathrm{I} .54(\mathrm{I} .07-2.24)$ & $\mathrm{I} .67(\mathrm{I} .10-2.53)$ & $\mathrm{I} .23(0.79-1.9)$ \\
Shortness of breath & $\mathrm{I} .88(\mathrm{I} .39-2.55)$ & $\mathrm{I} .80(\mathrm{I} .27-2.54)$ & $\mathrm{I} .75(\mathrm{I} .2 \mathrm{I}-2.54)$ \\
Wheezing & $\mathrm{I} .66(\mathrm{I} .12-2.46)$ & $\mathrm{I} .42(0.85-2.39)$ & $0.67(0.33-1.36)$ \\
Smoking $\geq 5$ PYs & $0.92(0.65-1.32)$ & & \\
Smoking $\geq 10 \mathrm{PYs}$ & $\mathrm{I} .73(\mathrm{I} .25-2.38)$ & & \\
\hline
\end{tabular}

Abbreviations: $\mathrm{Cl}$, confidence interval; PYs, pack-years.
Indeed, the prevalence of the disease in this subgroup was similar to the group of smokers and the subgroup of healthy smokers with smoking history at least $10 \mathrm{PYs}$. This last point emphasizes the importance of conducting epidemiological studies of nonsmokers with symptoms related to COPD in southern Italy that also investigate current prevalence and possible causes. In the subgroup of healthy smokers ( $\geq 5 \mathrm{PY}$ ) we found the lowest prevalence of COPD (7.1\%). This can be linked to the US Preventive Services Task Force for screening COPD, ${ }^{41}$ which stated that there is no real benefit of screening COPD in asymptomatic subjects, and also that early detection of COPD before the development of symptoms does not alter the course of the disease or improve patient outcomes. As shown in other large studies, ${ }^{36,42}$ in our population symptoms were more frequent in the subgroup of lower $\mathrm{FEV}_{1} \%$, and mean $\mathrm{FEV}_{1} \%$ was inversely related to the number of symptoms.

We showed that ORs for smoking history $\geq 10$ PYs was similar to ORs for the four symptoms considered in all subjects. This result warrants a COPD symptom-based approach not just about smoking when undergoing screening in a group of smoking and/or symptomatic volunteers. When considering the subgroups of smokers, the OR for cough remained the most likely symptom of COPD in smokers of $\geq 5$ PYs. Our data also showed that the probability of finding COPD in subjects with chronic symptoms, such as cough, sputum, shortness of breath, and wheezing, increased when considering smokers of at least $5 \mathrm{PYs}$, as opposed to the subgroup of smokers of at least 10 PYs. It is likely that in the latter group, the symptoms were related to smoking. In fact, it is known that some smokers without airflow obstruction nonetheless report cough, sputum production, and shortness of breath. ${ }^{2,43,44}$ The OR of shortness of breath was the highest considering all subjects, whereas it was reduced in subgroups of smokers. However, it has been previously described that COPD subjects have a tendency to underestimate shortness of breath, even when associated with significant compromise of everyday activities, ranking their disease as mild or moderate. ${ }^{45}$

Previous studies showed that symptoms were nonspecific and poor predictors of COPD. ${ }^{46-48}$ This occurs because the symptoms of COPD considered are often seen in subjects with normal lung function ${ }^{49}$ Similarly, our data reported that the presence of symptoms had low specificity. At the same time, high sensitivity was associated with the presence of at least one symptom: these data suggest that use of COPD-symptom questionnaires may be useful, even in a population of volunteers, to select a group of subjects to undergo screening 
Table 6 Sensitivity, specificity, PPVs, and NPVs of symptoms for COPD

\begin{tabular}{|c|c|c|c|c|c|c|c|c|c|c|c|c|}
\hline \multirow[t]{2}{*}{ Symptom } & \multicolumn{4}{|c|}{ All subjects $(n=I, 920)$} & \multicolumn{4}{|c|}{ Smokers $\geq 5$ PYs $(n=I, 495)$} & \multicolumn{4}{|c|}{ Smokers $\geq 10$ PYs $(n=1,085)$} \\
\hline & Sensitivity & Specificity & PPV & NPV & Sensitivity & Specificity & PPV & NPV & Sensitivity & Specificity & PPV & NPV \\
\hline Cough & 37 & 76 & 14 & 92 & 42 & 76 & 16 & 93 & 45 & 78 & 18 & 93 \\
\hline Sputum production & 22 & 85 & 13 & 91 & 23 & 85 & 14 & 91 & 23 & 80 & 14 & 89 \\
\hline Shortness of breath & 53 & 63 & 13 & 92 & 46 & 68 & 13 & 92 & 48 & 66 & 16 & 90 \\
\hline Wheezing & 19 & 88 & 14 & 91 & 13 & 90 & 13 & 90 & 7 & 90 & 8 & 88 \\
\hline One or more symptoms & 87 & 32 & II & 96 & 71 & 41 & II & 93 & 74 & 35 & 13 & 91 \\
\hline
\end{tabular}

Abbreviations: NPV, negative predictive value; PPV, positive predictive value; PY, pack-years.

spirometry. Moreover, symptoms considered individually, as is known, are characterized by low sensibility and high specificity, with the exception of dyspnea, probably because they are in many other respiratory and cardiovascular diseases. Also, the symptoms individually or combined (one or more) showed a low PPV and high NPV. Therefore, the absence of symptoms allows a prediction with good probability that an individual of this population is healthy. Nonetheless, excluding asymptomatic patients reduced the number of COPD diagnoses by $22.3 \%$. Sensitivity, specificity, PPV, and NPV in this study were similar when including in the analysis only subjects with a smoking history.

The totality of COPD subjects in our cohort were mild and moderate. These remarks may be relevant, because recent emerging evidence suggests that the decline in lung function occurs faster in the earlier stages of disease. ${ }^{13,50}$ Moreover, considering that exacerbations affecting all stages of COPD, as reported by the ECLIPSE study, ${ }^{51}$ are associated with an accelerated rate of decline in $\mathrm{FEV}_{1}$ and worsening of quality of life, ${ }^{52,53}$ it is easy to understand that early diagnosis is determinant not only in advanced cases but also in mild ones. Early diagnosis may provide the opportunity to prevent further deterioration in lung function, encouraging prompt smoking cessation, change in lifestyle, and treatment with inhaled BDs. In this regard, pharmacological therapy in moderate disease is associated with reduced decline of $\mathrm{FEV}_{1}$ and mortality, ${ }^{54,55}$ even after adjustments according to GOLD stage. ${ }^{56}$ Furthermore, O'Donnell et al showed that modest but consistent improvements in airway function, ${ }^{57}$ lung volume, and exercise dyspnea can be observed in mildCOPD smokers treated with BDs. Considering these benefits, BD treatment at early stages may reduce the frequency of exacerbations by the same mechanisms that prevent exacerbations in severe stages of the disease. ${ }^{58}$ Our data, in the light of these considerations, seem to support our screening approach.

Although the study population included patients of moderate and mild stages, Charlson Comorbidity Index scores increased in patients with COPD. This finding was in line with the evidence that the presence of comorbidities is not related to GOLD-stage severity, and thus it is necessary to investigate them even in early stages of the disease. ${ }^{59}$ Some limitations of our study have to be taken into account. First, we did not investigate the roles of passive smoking and occupational exposure. Moreover, we cannot rule out that some patients refused to report lung disease already known or did not have high-enough health literacy to understand or remember their diagnosis. In addition, we cannot exclude the presence of unknown asthma-COPD overlap syndrome cases among COPD patients and/or unknown asthmatic subjects in the not-COPD population. Finally, the low number of subjects of severe stage, certainly due to the population's recruitment method, limits the generalizability of our findings to the early stages of the disease.

In conclusion, voluntary public lung function screening programs in Italy may detect a large number of undiagnosed people with COPD in early stages. Screening programs on a voluntary basis like ours can counteract $\mathrm{FEV}_{1}$ decline precociously, and also, showing altered functional data in the population, can ease smoking cessation..$^{60}$ On the other hand, our results should be interpreted with caution, given the chance of disadvantages of COPD screening, such as the effects of overdiagnosis, the possibility of unnecessary treatment and potential side effects of the spirometry maneuvers. ${ }^{41}$ Symptoms are significantly associated with airway obstruction, but are not useful for predicting COPD in large voluntary screening programs, and exhibited low sensitivity, low PPV, and high NPV. By limiting the screening to smokers of at least 5 PYs and excluding nonsmokers with at least one symptom from the screening, the total number of COPD diagnoses may be reduced by $23.4 \%$. Furthermore, by excluding all asymptomatic patients, the number of COPD diagnoses was reduced by $22.3 \%$. Future COPD-screening studies should consider all symptomatic individuals, beyond history of smoking, to reduce the risk of underdiagnosis. 


\section{Acknowledgment}

The authors thank Dr Maiellari Michele for organizing the database.

\section{Disclosure}

The authors report no conflicts of interest in this work.

\section{References}

1. Celli BR, Decramer M, Wedzicha JA, et al. An official American Thoracic Society/European Respiratory Society statement: research questions in chronic obstructive pulmonary disease. Am J Respir Crit Care Med. 2015;191:e4-e27.

2. Vogelmeier CF, Criner GJ, Martinez FJ, et al. Global Strategy for the Diagnosis, Management, and Prevention of Chronic Obstructive Lung Disease 2017 Report: GOLD Executive Summary. Eur Respir J. 2017;49:1700214.

3. Istituto Superiore di Sanità. Il Fumo in Italia 2015 [Smoking in Italy in 2015]. 2015. Available from: http://www.progettocitex.it/wp-content/ uploads/2015/06/ISS-Rapporto-Fumo-2015.pdf. Accessed March 1, 2017. Italian.

4. Osman LM, Douglas JG, Garden C, et al. Indoor air quality in homes of patients with chronic obstructive pulmonary disease. Am J Respir Crit Care Med. 2007;176:465-472.

5. Eisner MD, Balmes J, Yelin EH, et al. Directly measured secondhand smoke exposure and COPD health outcomes. BMC Pulm Med. 2006;6:12

6. Melville AM, Pless-Mulloli T, Afolabi OA, Stenton SC. COPD prevalence and its association with occupational exposures in a general population. Eur Respir J. 2010;36:488-493.

7. Salvi SS, Barnes PJ. Chronic obstructive pulmonary disease in nonsmokers. Lancet. 2009;374:733-743.

8. Soriano JB, Zielinski J, Price D. Screening for and early detection of chronic obstructive pulmonary disease. Lancet. 2009;374:721-732.

9. Lindberg A, Bjerg-Bäcklund A, Rönmark E, Larsson LG, Lundbäck B. Prevalence and underdiagnosis of COPD by disease severity and the attributable fraction of smoking: report from the Obstructive Lung Disease in Northern Sweden studies. Respir Med. 2006;100:264-272.

10. Zielinski J, Bednarek M. Early detection of COPD in a high-risk population using spirometric screening. Chest. 2001;119:731-736.

11. Duvall K, Frank GW. Identifying chronic obstructive pulmonary disease in primary care of urban underserved patients: tools, applications, and challenges. J Natl Med Assoc. 2010;102:570-578.

12. van den Boom G, Rutten-van Mölken MP, Tirimanna PR, van Schayck CP, Folgering $\mathrm{H}$, van Weel C. Association between health-related quality of life and consultation for respiratory symptoms: results from the DIMCA programme. Eur Respir J. 1998;11:67-72.

13. Tantucci C, Modina D. Lung function decline in COPD. Int J Chron Obstruct Pulmon Dis. 2012;7:95-99.

14. Drummond MB, Hansel NN, Connett JE, Scanlon PD, Tashkin DP, Wise RA. Spirometric predictors of lung function decline and mortality in early chronic obstructive pulmonary disease. Am J Respir Crit Care Med. 2012;185:1301-1306.

15. Hudgel DW, Petty TL, Baidwan B, Harrison A. A community pulmonary disease screening effort: "Denver lung days". Chest. 1978;74:619-623.

16. Schoh RJ, Fero LJ, Shapiro H, et al. Performance of a new screening spirometer at a community health fair. Respir Care. 2002;47: $1150-1157$.

17. Tiberti S, Masedu F, Valenti M. BPCO: studio trasversale di prevalenza e programma di screening in un'area a rischio nel delta del Po [COPD: cross-sectional study of prevalence and screening program in a risk area of the Po River delta in Italy]. Ann Ig. 2010;22:583-599. Italian.

18. Cricelli C, Mazzaglia G, Samani F, et al. Prevalence estimates for chronic diseases in Italy: exploring the differences between self-report and primary care databases. J Public Health Med. 2003;25:254-257.
19. Viegi G, Matteelli G, Angino A, et al. The proportional Venn diagram of obstructive lung disease in the Italian general population. Chest. 2004; 126:1093-1101.

20. Belleudi V, Agabiti N, Kirchmayer U, et al. Definizione e validazione di un modello predittivo per l'identificazione di pazienti affetti da broncopneumopatia cronica ostruttiva (BPCO) a partire dai sistemi informativi sanitari [Definition and validation of a predictive model to identify patients with chronic obstructive pulmonary disease (COPD) from administrative databases]. Epidemiol Prev. 2012;36:162-171. Italian.

21. European Environment Agency. Air Quality in Europe - 2016 Report. Copenhagen: EEA; 2016.

22. Charlson ME, Pompei P, Ales KL, MacKenzie CR. A new method of classifying prognostic comorbidity in longitudinal studies: development and validation. J Chronic Dis. 1987;40:373-383.

23. Lee C, Kahende J. Factors associated with successful smoking cessation in the United States, 2000. Am J Public Health. 2007;97:1503-1509.

24. US Food and Drug Administration. Summary of safety and effectiveness: Spirolab II. 2006. Available from: https://www.accessdata.fda gov/cdrh_docs/pdf5/K052140.pdf. Accessed March 1, 2017.

25. Perillo M, Boschetti PS. Spirolab II User's Manual. Revision 2. Waukesha (WI): Medical International Research; 2001.

26. Miller MR, Hankinson J, Brusasco V, et al. Standardisation of spirometry. Eur Respir J. 2005;26:319-338.

27. Quainer PH. Standardized lung function testing. Bull Eur Physiopathol Respir. 1983;19:1-95.

28. Tavakol M, Dennik R. Making sense of Cronbach's alpha. Int J Med Educ. 2011;2:53-55.

29. Puglia: Libro Bianco. Esperienze di gestione delle malattie respiratorie nella regione Puglia. Tendenze Nuove n.1-2015 [Puglia: White Paper. Experiences in management of respiratory diseases in the Puglia region. New tendencies n.1-2015]. Passoni Editore. Available from: http:// www.fsk.it/attach/Content/Tendenzenuove/5836/o/tendenze_0115.pdf. Accessed June 1, 2016. Italian.

30. Approvazione percorso diagnostico terapeutico per la diagnosi e la terapia di ASMA e BPCO [Approval of a therapeutic and diagnostic path for diagnosis and therapy of ASMA and COPD]; 2013. Available from: http://www.forumriskmanagement.it/images/FORUMRISK11/ LABORATORIO-PDTA/REGIONI/PUGLIA/Deliberazione_ Giunta_regionale_PDTA_BPCO_2013.pdf. Accessed March 1, 2017. Italian.

31. McIvorRA, TashkinDP. Underdiagnosis of chronic obstructive pulmonary disease: a rationale for spirometry as a screening tool. Can Respir J. 2001;8:153-158.

32. Van Schayck CP, Loozen JM, Wagena E, Akkermans RP, Wesseling GJ Detecting patients at a high risk of developing chronic obstructive pulmonary disease in general practice: cross sectional case finding study. BMJ. 2002;324:1370.

33. van den Boom G, van Schayck CP, van Möllen MP, et al. Active detection of chronic obstructive pulmonary disease and asthma in the general population: results and economic consequences of the DIMCA program. Am J Respir Crit Care Med. 1998;158:1730-1738.

34. Kida K, Wakabayashi R, Mizuuchi T, Murata A. Screening for suspected chronic obstructive pulmonary disease with an elevenitem pre-interview questionnaire (11-Q). Intern Med. 2006;45: 1201-1207.

35. Zhong N, Wang C, Yao W, et al. Prevalence of chronic obstructive pulmonary disease in China: a large, population-based survey. Am J Respir Crit Care Med. 2007;176:753-760.

36. Ohar JA, Sadeghnejad A, Meyers DA, Donohue JF, Bleecker ER. Do symptoms predict COPD in smokers? Chest. 2010;137:1345-1353.

37. Bednarek M, Maciejewski J, Wozniak M, Kuca P, Zielinski J. Prevalence, severity and underdiagnosis of COPD in the primary care setting. Thorax. 2008;63:402-407.

38. Whittemore AS, Perlin SA, Di Ciccio Y. Chronic obstructive pulmonary disease in lifelong nonsmokers: results from NHANES. Am J Public Health. 1995;85:702-706. 
39. Birring SS, Brightling CE, Bradding P, et al. Clinical, radiologic, and induced sputum features of chronic obstructive pulmonary disease in nonsmokers: a descriptive study. Am J Respir Crit Care Med. 2002; 166:1078-1083.

40. Peña VS, Miravitlles M, Gabriel R, et al. Geographic variations in prevalence and underdiagnosis of COPD: results of the IBERPOC multicentre epidemiological study. Chest. 2000;118:981-989.

41. Siu AL, Bibbins-Domingo K, Grossman DC, et al. Screening for chronic obstructive pulmonary disease: US Preventive Services Task Force Recommendation Statement. JAMA. 2016;315:1372-1377.

42. Buist AS, Connett JE, Miller RD, Kanner RE, Owens GR, Voelker HT. Chronic Obstructive Pulmonary Disease Early Intervention Trial (Lung Health Study): baseline characteristics of randomized participants. Chest. 1993;103:1863-1872.

43. Martinez $\mathrm{CH}$, Kim V, Chen Y, et al. The clinical impact of nonobstructive chronic bronchitis in current and former smokers. Respir Med. 2014;108:491-499.

44. van der Molen T, Willemse BW, Schokker S, ten Hacken NH, Postma DS, Juniper EF. Development, validity and responsiveness of the Clinical COPD Questionnaire. Health Qual Life Outcomes. 2003;1:13.

45. Rennard S, Decramer M, Calverley PM, et al. Impact of COPD in North America and Europe in 2000: subjects' perspective of Confronting COPD International Survey. Eur Respir J. 2002;20:799-805.

46. Medbø A, Melbye H. What role may symptoms play in the diagnosis of airflow limitation? A study in an elderly population. Scand J Prim Health Care. 2008;26:92-98.

47. Methvin JN, Mannino DM, Casey BR. COPD prevalence in southeastern Kentucky: the Burden of Lung Disease study. Chest. 2009;135: 102-107.

48. Chang JH, Lee JH, Kim MK, et al. Determinants of respiratory symptom development in patients with chronic airflow obstruction. Respir Med. 2006;100:2170-2176.

49. Wilt TJ, Niewoehner D, Kim C, et al. Use of spirometry for case finding, diagnosis, and management of chronic obstructive pulmonary disease (COPD). Evid Rep Technol Assess (Summ). 2005;121:1-7.

50. Casanova C, de Torres JP, Aguirre-Jaíme A, et al. The progression of chronic obstructive pulmonary disease is heterogeneous: the experience of the BODE cohort. Am J Respir Crit Care Med. 2011;184: 1015-1021
51. Hurst JR, Vestbo J, Anzueto A, et al. Susceptibility to exacerbation in chronic obstructive pulmonary disease. $N$ Engl J Med. 2010;363: $1128-1138$

52. Donaldson GC, Seemungal TA, Bhowmik A, Wedzicha JA. Relationship between exacerbation frequency and lung function decline in chronic obstructive pulmonary disease. Thorax. 2002;57:847-852.

53. Seemungal TA, Donaldson GC, Paul EA, et al. Effect of exacerbation on quality of life in patients with chronic obstructive pulmonary disease. Am J Respir Crit Care Med. 1998;157:1418-1422.

54. Decramer M, Celli B, Kesten S, et al. Effect of tiotropium on outcomes in patients with moderate chronic obstructive pulmonary disease (UPLIFT): a prespecified subgroup analysis of a randomised controlled trial. Lancet. 2009;374:1171-1178.

55. Celli BR, Thomas NE, Anderson JA, et al. Effect of pharmacotherapy on rate of decline of lung function in chronic obstructive pulmonary disease: results from the TORCH study. Am J Respir Crit Care Med. 2008; 178:332-338.

56. Celli B, Decramer M, Kesten S, et al. Mortality in the 4-year trial of tiotropium (UPLIFT) in patients with chronic obstructive pulmonary disease. Am J Respir Crit Care Med. 2009;180:948-955.

57. O'Donnell DE, Laveneziana P, Ora J, Webb KA, Lam YM, Ofir D. Evaluation of acute bronchodilator reversibility in patients with symptoms of GOLD stage I COPD. Thorax. 2009;64:216-223.

58. Wedzicha JA, Calverley PM, Seemungal TA, et al. The prevention of chronic obstructive pulmonary disease exacerbations by salmeterol/ fluticasone propionate or tiotropium bromide. Am J Respir Crit Care Med. 2008;177:19-26.

59. Echave-Sustaeta JM, Casanova LC, Cosio BG, Soler-Cataluña JJ, Garcia-Lujan R, Ribera X. Comorbidity in chronic obstructive pulmonary disease: related to disease severity? Int J Chron Obstruct Pulmon Dis. 2014;9:1307-1314.

60. Risser NL, Belcher DW. Adding spirometry, carbon monoxide, and pulmonary symptom results to smoking cessation counseling: a randomized trial. J Gen Intern Med. 1990;5:16-22.
International Journal of COPD

\section{Publish your work in this journal}

The International Journal of COPD is an international, peer-reviewed journal of therapeutics and pharmacology focusing on concise rapid reporting of clinical studies and reviews in COPD. Special focus is given to the pathophysiological processes underlying the disease, intervention programs, patient focused education, and self management protocols.

\section{Dovepress}

This journal is indexed on PubMed Central, MedLine and CAS. The manuscript management system is completely online and includes a very quick and fair peer-review system, which is all easy to use. Visit http://www.dovepress.com/testimonials.php to read real quotes from published authors. 